\title{
GAMBARAN KUALITAS KEHIDUPAN LANSIA DI GIANYAR BALI
}

\section{Ni Putu Saraswati Wardani ${ }^{1}$, Fransisca Iriani Roesmala Dewi ${ }^{2}$}

\author{
${ }^{1}$ Program Studi Sarjana Psikologi, Universitas Tarumanagara, Jakarta \\ Email: niputu.705150156@stu.untar.ac.id \\ ${ }^{2}$ Fakultas Psikologi, Universitas Tarumanagara, Jakarta \\ Email:fransiscar@fpsi.untar.ac.id
}

Masuk : 23-06-2020, revisi: 25-10-2020, diterima untuk diterbitkan : 31-10-2020

\begin{abstract}
Bali as one of the cities with the fourth rank has the largest number of elderly people in Indonesia. Religious, social and cultural life has a very strong influence on the quality of life of the elderly. The purpose of this study was to describe the quality of life of the elderly in Gianyar, Bali. This study uses a phenomenological qualitative approach with data collection techniques, interviews and observations. The subjects involved in this study were eight elderly individuals, eight subjects consisted of 4 men and 4 women, aged 60-70 years, with low educational status. The majority of participants have a partner (married), and still have a job as a daily activity. five out of eight elderly felt that the income they earned was sufficient to meet their daily needs, while three elderly felt that the income they earned could not meet their daily needs. The results of this study illustrate that eight elderly people have been able to achieve a quality life in 6 aspects, namely social relationships (active in social life); psychological well-being (positive feelings, self-worth); spiritual (gratitude), independence (organize and decide on their own activities, be financially independent); self-empowerment (beneficial for others. involved in decision making for family or community); environment (facilities and infrastructure or health care facilities). Meanwhile, one other aspect, namely physical health is defined as a condition of the body that is not fit and visual disturbances are often sick, so that it is perceived that their life is less qualified.
\end{abstract}

Keywords: quality of life, elderly, Bali, phenomenology

\begin{abstract}
ABSTRAK
Bali sebagai salah satu kota dengan peringkat keempat yang memiliki jumlah penduduk lansia terbanyak di Indonesia. Kehidupan beragama, sosial dan budaya yang sangat kuat mempengaruhi kualitas kehidupan lansia. Tujuan Penelitian ini untuk mendeskripsikan kualitas kehidupan lansia di Gianyar, Bali. Penelitian ini menggunakan pendekatan kualitatif fenomenologi dengan teknik pengumpulan data wawancara dan observasi. Subyek yang terlibat dalam penelitian in adalah delapan individu lansia, delapan subyek terdiri dari 4 orang laki-laki dan 4 perempuan, berusia antara 60-70 tahun, dengan status pendidikan yang rendah. Mayoritas partisipan memiliki pasangan (menikah), serta masih memiliki pekerjaan sebagai aktivitas kesehariannya. Lima dari delapan lansia merasakan bahwa penghasilan yang didapatkan cukup untuk memenuhi kebutuhannya sehari-hari sedangkan tiga lansia merasa bahwa penghasilan yang didapatkan kurang dapat memenuhi kebutuhannya. Hasil penelitian ini menggambarkan bahwa delapan lansia telah mampu mencapai kehidupan yang berkualitas pada 6 aspek yaitu hubungan sosial (aktif dalam kehidupan bermasyarakat); kesejahteraan psikologis (perasasan positif, keberhargaandiri); spiritual (rasa syukur), kemandirian (mengatur dan memutuskan aktivitas sendiri, mandiri secara finansial); pemberdayaan diri (bermanfaat untuk orang lain. dilibatkan dalam pengambilan keputusan untuk keluarga atau masyarakat); lingkungan (sarana dan prasarana atau fasilitas perawatan kesehatan). Sementara satu aspek lainnya, yakni kesehatan fisik dimaknai dengan keadaan tubuh yang kurang fit dan gangguan penglihatan sering sakit, sehingga dipersepsikan kehidupannya kurang berkualitas.
\end{abstract}

Kata Kunci: kualitas kehidupan, lansia, Bali, fenomenologi

\section{PENDAHULUAN}

Jumlah penduduk lanjut usia bertambah dengan pesat, baik pada negara maju maupun negara berkembang. Pada tahun 2010 jumlah lansia di Indonesia sebesar 18,1 juta jiwa (7,6\% dari total penduduk) dan pada tahun 2012 naik menjadi 18,55 juta jiwa (7,78\% dari total penduduk) (BPS, 2012). Pada tahun 2013 PBB mencatat jumlah lansia di Indonesia berada pada urutan 108 dari 
seluruh negara di dunia (Sutari, 2017). Pada tahun 2014, jumlah penduduk lanjut usia di Indonesia meningkat menjadi 18,781 jiwa (Kementerian Kesehatan Republik Indonesia, 2017).

Pada tahun 2017 jumlah penduduk lansia meningkat dengan jumlah sebesar 23,66 juta jiwa (9.03\%) (Kementerian Kesehatan Republik Indonesia, 2017). Bali masuk ke dalam peringkat 4 provinsi yang memiliki penduduk lansia terbanyak di Indonesia. Berdasarkan data Kementerian Kesehatan Republik Indonesia (2017) Bali memiliki jumlah penduduk lansia dengan persentase sebesar $10.42 \%$. Salah satu kabupaten di Provinsi Bali yang mengalami peningkatan jumlah lansia adalah Kabupaten Gianyar dengan jumlah lansia pada tahun 2012 sebesar 47.647 jiwa dan pada tahun 2013 sebanyak 49.172 Jiwa (Dinas Kesehatan Kabupaten Gianyar, 2013).

Dalam lingkup budaya Bali, lansia memiliki kewajiban untuk melakukan kegiatan gotongroyong atau yang disebut dengan ngayah (Sena, 2010). Tradisi ngayah ini dilakukan dengan membantu keluarga lain di lingkungan tempat tinggalnya untuk mempersiapkan upacara adat. Jika tidak melakukannya, lansia akan menerima sanksi sosial berupa pengucilan atau sanksi adat berupa denda dan konsekuensi tidak diberikan ijin melakukan upacara adat (Ayuningtias, 2018)

Bali memiliki sistem budaya pengaturan tempat tinggal untuk lansia, secara adat masyarakat lebih mengutamakan lansia tinggal bersama anak laki-laki terkecil (Wiyono \& Djutaharta, 2019). Kabupaten Gianyar memiliki kegiatan yang dikhususkan untuk lansia. Kegiatan tersebut bernama "Gianyar Peduli Lansia", kegiatan ini adalah suatu kegiatan untuk memberikan bantuan kepada lansia-lansia yang kurang mampu (Pemerintahan Kabupaten Gianyar, 2014). Selain itu kegiatan lain yang ditunjukkan untuk lansia adalah "Gerakan Lansia Berbasis Masyarakat". Kegitanini bertujuan untuk memberdayakan lansia sesuai dengan keahlian masing-masing lansia. Selain itu di kabupaten Gianyar juga melakukan sosialisasi peningkatan kualitas hidup lansia potensial, sosialisasi yang dilakukan dengan mengadakan kegiatan senam otak untuk lansia, kegiatan ini berupa permainan yang intinya mampu melatih daya ingat, konsentrasi maupun gerak tubuh ringan (Pemerintahan Kabupaten Gianyar, 2017).

Kualitas kehidupan adalah evaluasi subyektif kemampuan individu yang dipengaruhi oleh potensi fisik, mental, dan sosial, dimana seseorang mampu menyampaikan keseluruhan kesejahteraan dan mencakup aspek-aspek seperti kebahagiaan dan kepuasan dengan kehidupan secara keseluruhan (Sun et al, 2014). Kualitas kehidupan dipengaruhi oleh kondisi fisik individu, psikologis, tingkat kemandirian, serta hubungan individu dengan lingkungan (Yulianti, Baroya, \& Ririanty, 2014). Hidup lansia yang berkualitas merupakan kondisi fungsional lansia pada kondisi optimal, sehingga mereka bisa menikmati masa tuanya dengan penuh makna, membahagiakan dan berguna (Sutikno, 2011).

Menurut World Health Organization (1996), kualitas hidup adalah persepsi individu mengenai posisi individu dalam hidup sesuai konteks budaya dan sistem nilai yang dianutnya, dimana individu hidup dan hubungannya dengan harapan, tujuan, standar yang ditetapkan dan perhatian dari individu. Kualitas kehidupan memiliki enam dimensi yaitu kesehatan fisik, kesejahteraan psikologis, tingkat kemandirian, hubungan sosial, lingkungan, dan spiritual. Lalu pada perkembangannya WHO mempersingkat dimensi kualitas kehidupan menjadi empat domain yang terdapat di dalam WHO-QOL-BREF, domain tersebut yaitu kesehatan fisik, psikologis, hubungan sosial, dan lingkungan. Dewi, Rostiana, dan Rumawas (2018) mengembangkan alat ukur kualitas kehidupan lansia di Indonesia dan menemukan tiga dimensi tambahan dari empat dimensi sebelumnya. Ketujuh dimensi tersebut adalah dimensi fisik, psikologis, kemandirian, pemberdayaan diri, lingkungan, hubungan sosial dan spiritual. 
Kesehatan fisik adalah kemampuan individu melakukan aktivitas mencakup aktivitas sehari-hari, meliputi rasa sakit dan merasa tidak nyaman, energi dan rasa lelah, kualitas tidur dan istirahat, ketergantungan dengan pengobatan mobilitas, serta bekerja (WHO, 1998).

Dimensi kesejahteraan psikologis terkait keadaan mental individu. Keadaan mental mengarah pada mampu atau tidaknya individu menyesuaikan diri terhadap berbagai tuntutan perkembangan sesuai dengan kemampuannya, meliputi perasaan positif, perasaan negatif, self- esteem, kemampuan berpikir, mengingat dan berkonsentrasi, body image, agama dan kepercayaan pribadi (WHO, 1998). Hubungan sosial yaitu hubungan antara dua individu atau lebih yang mana tingkah laku individu tersebut akan saling mempengaruhi, mengubah atau memperbaiki tingkah laku individu lainnya meliputi personal, seks, dan dukungan sosial.

Lingkungan yaitu tempat tinggal individu. Termasuk keadaan, ketersediaan tempat tinggal untuk melakukan segala aktivitas kehidupan, sarana dan prasarana. Hubungan dengan lingkungan mencakup sumber keuangan, kebebasan, keamanan dan keselamatan fisik, perawatan kesehatan dan perawatan sosial termasuk aksesibilitas dan kualitas, lingkungan rumah, kesempatan untuk mendapatkan berbagai informasi baru maupun keterampilan, partisipasi dan kesempatan untuk melakukan rekreasi dan kegiatan yang menyenangkan di waktu luang, dan lingkungan fisik seperti polusi, kebisingan, keadaan air atau iklim, serta transportasi (WHO, 1998). Dimensi kemandirian adalah dorongan sendiri untuk kebutuhannya, termasuk seberapa mampu partisipan dalam mengatur aktivitas sendiri, mandiri secara finansial, dapat memenuhi kebutuhan sendiri, tidak bergantung pada anak, dan merasa masih dibutuhkan (Dewi et al., 2017). Dimensi spiritual adalah mengembangkan dirinya secara utuh. Seberapa mampu partisipan dalam menerima kondisi fisik/sosial, kesabaran, bersyukur, dan melakukanibadah kepada Tuhan Yang Maha Esa (Dewi et al., 2017). Dimensi pemberdayaan diri adalah keinginan untuk diberdayakan meskipun mereka sudah berada dalam usia lanjut. Seberapa mampu partisipan dalam meningkatkan kepercayaan diri dan termotivasi mengejar tujuan.

Kualitas hidup lanjut usia merupakan suatu komponen yang kompleks, mencakup usia harapan hidup, kepuasan dalam kehidupan, kesehatan psikologis dan mental, fungsi kognitif, kesehatan dan fungsi fisik, pendapatan, kondisi tempat tinggal, dukungan sosial dan jaringan sosial (Sutikno 2011). Kualitas kehidupan lansia di Indonesia menurut Index Global Age Watch berada pada peringkat 71 dari 96 negara (Dahono, 2014). Kualitas hidup lansia dapat dinilai dari berbagai perspektif (Fernandez-Ballestreros dalam Sirgy 2012). Kualiats hidup lansia dapat dilihat dari penilaian kepuasaan hidup secara umum atau keseluruhan (Spreitzer \& Snyder dalam Sirgy, 2012). Kualitas hidup lanjut usia merupakan suatu komponen yang kompleks, mencakup usia harapan hidup, kepuasan dalam kehidupan, Kesehatan psikologis dan mental, fungsi kognitif, kesehatan dan fungsi fisik, pendapatan, kondisi tempat tinggal, dukungan sosial dan jaringan sosial (Sutikno 2011). Kualitas hidup lebih menekankan pada persepsi terkait dengan kepuasan terhadap posisi dan keadaan lansia di dalam hidupnya, dan cenderung dipengaruhi oleh sejauh mana tercapainya kebutuhan ekonomi dan sosial, serta perkembangan lansia dalam kehidupannya (Yulianti et al., 2014). Kualitas hidup lansia yang optimal bisa diartikan sebagai kondisi fungsional berada pada kondisi maksimum atau optimal, sehingga memungkinkan mereka bisa menikmati masa tuanya dengan penuh makna, membahagiakan, berguna dan berkualitas (Sutikno, 2011). Penelitian yang dilakukan oleh Wikananda (2017) di Desa Sanding Tampaksiring menemukan bahwa lansia yang tidak bekerja memiliki kualitas hidup yang buruk dibandingkan dengan lansia yang masih bekerja, hal ini berkaitan dengan penghasilan dan pemenuhan kebutuhan lansia yang berkaitan dengan kualitas kehidupan serta interaksi sosialnya. Selain itu ditemukan juga bahwa lansia yang memiliki pasangan hidup dan Penelitian lain yang 
dilakukan di Desa Jimbaran menemukan bahwa kualitas kehidupan para lansia di sana hampir setengahnya masuk dalam kategori buruk. Hal ini karena kemampuan finansial lansia yang buruk dan dukungan keluarga yang tidak baik (Artini, Prihandhani, \& Martini, 2017). Penelitian yang dilakukan oleh Baernholdt, Yan, Hinton, Rose, \& Mattos (2012) menunjukkan bahwa kualitas kehidupan lansia yang tinggal di kota lebih rendah dibandingkan dengan lansia yang tinggal di kota, tetapi lansia di desa memiliki fungsi sosial yang lebih rendah dibandingkan dengan lansia yang tinggal di kota.

Berdasarkan data yang telah dijabarkan di atas, Indonesia masuk ke dalam daftar negara yang memiliki penduduk lansia terbanyak dan masuk era penduduk karena jumlah penduduk lansia diatas 7\%. Posisi keempat provinsi yang memiliki jumlah lansia terbanyak di Indonesia adalah Bali. Salah satu kabupaten yang mengalami peningkatan dan memiliki banyak kegiatan yang ditunjukan untuk lansia adalah kabupaten Gianyar. Lansia di kabupaten Gianyar memiliki kegiatan pemberdayaan diri dan kesenian untuk lansia. Dengan kawasan Gianyar yang memiliki banyak persawahan, banyak lansia yang masih aktif bekerja di bidang pertanian. Melihat fenomena serta data yang ada di atas, peneliti tertarik untuk meneliti "Gambaran Kualitas Kehidupan Lansia di Gianyar Bali."

\section{METODE PENELITIAN}

\section{Subyek penelitian}

Subyek dari penelitian ini adalah individu yang berusia 60 tahun ke atas dengan kondisi fisik dan mental yang baik serta mampu memberikan respon yang baik. Partisipan dalam penelitian ini berjumlah 8 orang terdiri dari 4 orang perempuan dan 4 orang laki-laki.

\section{Instrumen penelitian}

Penelitian ini menggunakan metode kualitatif fenomenologi untuk mengetahui bagaimana seorang lansia memaknai kualitas kehidupannya. Metode dalam penelitian ini menggunakan wawancara mendalam dan observasi pada setiap subyek. Dalam penelitian ini, instrumen yang digunakan yaitu pedoman wawancara yang dilengkapi dengan informed consent dan peralatan penelitian berupa handphone yang digunakan untuk merekam sesi wawancara. Teknik pengambilan sampel yang digunakan dalam penelitian ini adalah purposive sampling karena penulis ingin mencari subjek yang sesuai dengan kriteria yang dibutuhkan untuk penelitian ini.

\section{Prosedur penelitian}

Pedoman wawancara ini dibuat sebelum penelitian dilaksanakan agar pertanyaan-pertanyaan yang disampaikan peneliti terstruktur dan sesuai dengan tujuan penelitian. Selain itu peneliti juga mulai menyiapkan informed consent yang digunakan untuk menyatakan kesediaan subjek atas keterlibatannya dalam penelitian dan subjek memiliki kuasa penuh atas segala data yang diberikannya dalam penelitian ini.Tahap selanjutnya menemukan subjek yang sesuai dengan kriteria. Setelah mendapatkan subjek yang sesuai kriteria peneliti membuat perjanjian waktu dan tempat untuk mewawancarai subyek. Setelah mulai melakukan pendekatan awal kepada subjek agar saat dilakukan wawancara selanjutnya subjek sudah mulai terbuka dengan peneliti. Setelah melakukan pendekatan awal, peneliti mulai melakukan wawancara dengan terlebih dahulu memberikan kesempatan subyek untuk mengisi informed consent sebagai tanda kesediaan untuk menjadi subyek penelitian dalam penelitian ini dan kemudian peneliti mulai mewawancarai subyek. Setelah melakukan wawancara pada semua subyek peneliti mengolah jawaban subyek ke dalam bentuk verbatim dan koding, serta kemudian menganalisis dengan teori yang peneliti gunakan. 
Analisis data meliputi 6 tahapan (Creswell, 2013) adalah sebagai berikut: (1) Mengolah dan mempersiapkan data yang akan dianalisis. Pada tahap ini penulis membuat transkrip/verbatim dari hasil wawancara yang berisi percakapan antar penulis dengan partisipan; (2) Membaca keseluruhan data. Pada tahap ini penulis mulai membaca keseluruhan data sehingga didapatkan makna secara keseluruhan dari data yang diperoleh. (3) Melakukan koding data. Pada tahap ini penulis mulai mengolah data dengan memberikan koding pada data verbatim wawncara. Tujuan pemberian koding ini agar memudahkan penulis dalam menemukan letak informasi penting yang muncul dari hasil verbatim wawancara. (4) Menerapkan koding untuk menentukan kategori dan tema yang akan dianalisis. Tahapan selanjutnya setelah penulis memberikan koding, penulis akan menentukan kategorisasi tema sesuai dengan tujuan penelitian yang ingin dicapai. (5) Menyajikan tema-tema kedalam bentuk narasi atau laporan. Pada tahap ini penulis menuangkan hasil penelitian dalam bentuk narasi. (6) Menginterpretasi atau memaknai data. Pada tahapan ini peneliti akan melakukan analisis hasil penelitian dengan pustaka atau teori yang ada.

\section{HASIL DAN PEMBAHASAN}

Dalam penelitian ini, tujuh dari delapan subyek merasa tidak puas dengan kesehatan fisiknya karena ketujuh subyek mengalami gangguan kesehatan yang membuat aktivitasnya terganggu, selain itu mereka juga merasakan penurunan energi. Dari delapan subyek hanya satu subyek yang merasakan kepuasaan pada kesehatannya yaitu subyek NS, walaupun pernah mengalami operasi tetapi subyek NS merasa puas dengan kesehatannya saat ini. Tabel 1 menunjukkan gambaran umum subyek penelitian.

Tabel 1. Gambaran Umum Subyek Penelitian

\begin{tabular}{cllll}
\hline SUBYEK & $\begin{array}{l}\text { USIA } \\
\text { (th) }\end{array}$ & \multicolumn{1}{c}{ PEKERJAAN } & PENDIDIKAN & STATUS \\
\hline WL & 67 & Petani & SMP & Menikah \\
\hline NS & 65 & Pemborong Bangunan & SMA & Menikah \\
\hline KM & 65 & Pedagang & SMP & Menikah \\
\hline NR & 68 & Pensiunan Guru & S-1 & Menikah \\
\hline NK & 70 & Petani & SD & Menikah \\
\hline WR & 60 & Petani dan Buruh & SD & Menikah \\
\hline WK & 65 & Ibu Rumah Tangga & SD & Menikah \\
\hline WM & 64 & Petani dan Buruh Bangunan & SD & Janda \\
\hline
\end{tabular}

Delapan subyek dalam penelitian ini memiliki kepuasaan terhadap kesejahteraan psikologis. Kedelapan subyek memiliki kepuasaan terhadap semua komponen yang ada di dalam dimensi kesejahteraan psikologis. Kedelapan subyek memiliki perasaan positif dan negatif yang dirasakan berbeda-beda pada masa tuanya. Kedelapan subyek juga memiliki kemampuan mengingat dan konsentrasi yang baik di masa tuanya. Tujuh dari delapan subyek menerima dengan baik perubahan fisik yang terjadi pada masa tuanya saat ini. Kedelapan subyek memiliki semangat untuk terus menjalani kehidupannya. Tiga dari delapan subyek yaitu subyek WL, NS, dan NR menikmati kehidupannya dengan menjalankan hobi yang dimiliki, sedangkan lima subyek lain yaitu subyek KM, NR, WR, WK dan WM menikmati kehidupannya dengan bertemu cucu-cucunya.

Berdasarkan wawancara yang dilakukan diketahui bahwa kedelapan subyek memiliki hubungan yang baik dengan keluarga dan orang-orang di sekitar tempat tinggalnya. Kedelapan subyek juga mendapatkan dukungan yang baik dari keluarga serta orang lain di lingkungan subyek, saat sedang menghadapi masalah dan memerlukan bantuan kedelapan subyek mendapatkan dukungan berupa semangat, materi serta saran mengenai masalah yang sedang dihadapi. Dengan adanya 
hubungan sosial yang baik dengan orang-orang di sekitarnya, kedelapan subyek merasakan kepuasaan dalam hubungan sosial yang dijalani.

Tidak semua subyek saat ini merasakan kepuasaan terhadap kondisi lingkungan tempat tinggal. Tujuh dari delapan subyek merasakan kepuasaan terhadap lingkungannya karena merasa nyaman dan merasakan kebersihan dari lingkungannya. Sedangkan satu subyek yaitu WM merasa kurang puas dengan lingkungannya walaupun memiliki kenyamanan pada lingkungannya. Selain itu dari delapan subyek hanya lima orang subyek yaitu WL, NS, NR, KM, dan WK yang merasakan kepuasaan pada penghasilannya sedangkan tiga subyek lainnya yaitu NK, WR, dan WM merasa ketidakpuasaan pada penghasilan yang diterima.

Enam orang subyek yaitu subyek WL, NS, KM, NR, WR, dan WM dapat mengatur keuangan dan aktivitasnya secara mandiri sedangkan dua subyek lainnya yaitu subyek WM dapat mengatur aktivitasnya secara mandiri tetapi keuangan yang dimiliki diatur oleh suaminya sedangkan untuk subyek NK, aktivitas dan keuangannya saat ini diatur bersama dengan anak dan istri. Walaupun tidak semua subyek dapat dengan mandiri mengatur aktivitas dan keuangannya tetapi semua subyek merasa puas dengan kemandirian yang dimiliki.

Kedelapan subyek aktif untuk melakukan persembahyangan dan mengikuti kegiatan agama. Kedelapan subyek juga merasakan bahwa agama yang diyakininya memiliki pengaruh di dalam kehidupannya sehari-hari. Berdasarkan wawancara yang dilakukan diketahui juga bahwa semua subyek merasakan kepuasan terhadap kehidupan spiritual karena merasa bahwa agama yang diyakininya berpengaruh terhadap kehidupannya sehari-hari

Subyek penelitian juga merasa masih diberdayakan pada usianya saat ini karena merasa bahwa saran dan ide-ide yang diberikan oleh mereka masih didengarkan dan diterima baik oleh masyarakat di lingkungan subyek serta anak-anak subyek. Tujuh dari delapan subyek yaitu subyek WL, NS, KM, NK, NR, WR, WK merasa masih bermanfaat untuk orang lain karena masih dapat membantu orang di sekitar mereka, sedangkan satu subyek yaitu subyek WM merasa sudah tidak bermanfaat untuk orang lain karena usianya yang sudah tua. Berdasarkan wawancara yang dilakukan delapan subyek merasakan kepuasan pada dimensi pemberdayaan diri yang dirasakannya karena masih merasa diberdayakan walaupun usia semua subyek sudah menua. Menurut Sirgy (2012) kualitas hidup dapat dikatakan tinggi jika para lansia merasa bahwa kebutuhan perkembangannya terpenuhi. Kelley-Gillespie (dikutip dalam Sirgy, 2012) melakukan beberapa kajian menyeluruh mengenai kualitas hidup yang berkaitan dengan lansia dan behasil mempersatukan banyak literature menjadi enam domain yaitu; (1) kesejahteraan sosial, (2) kesejahteraan fisik, (3) kesejahteraan psikologis, (4) kesejahteraan kognitif, (5) kesejahteraan spiritual, dan (6) kesejahteraan lingkungan.

\section{Kesejahteraan psikologis}

Dimensi kesejahteraan psikologis terkait keadaan mental individu. Keadaan mental mengarah pada mampu atau tidaknya individu menyesuaikan diri terhadap berbagai tuntutan perkembangan sesuai dengan kemampuannya, meliputi perasaan positif, perasaan negatif, self-steem, kemampuan berpikir, mengingat dan berkonsentrasi, body image, agama dan kepercayaan pribadi (WHO, 1998). Delapan subyek dalam penelitian ini memiliki kepuasaan terhadap kesejahteraan psikologis. Kedelapan subyek memiliki kepuasaan terhadap semua komponen yang ada di dalam dimensi kesejahteraan psikologis. Kedelapan subyek memiliki perasaan positif dan negatif yang dirasakan berbeda-beda pada masa tuanya. Kedelapan subyek juga memiliki kemampuan mengingat dan konsentrasi yang baik di masa tuanya. Tujuh dari delapan 
subyek menerima dengan baik perubahan fisik yang terjadi pada masa tuanya saat ini. Kedelapan subyek memiliki semangat untuk terus menjalani kehidupannya. Tiga dari delapan subyek yaitu subyek WL, NS, dan NR menikmati kehidupannya dengan menjalankan hobby yang dimiliki sedangkan lima subyek lain yaitu subyek KM, NR, WR, WK dan WM menikmati kehidupannya dengan bertemu cucu-cucunya.

\section{Hubungan sosial}

Hubungan sosial yaitu hubungan antara dua individu atau lebih yang mana tingkah laku individu tersebut akan saling mempengaruhi, mengubah atau memperbaiki tingkah laku individu lainnya meliputi personal, seks, dan dukungan sosial (WHO, 1998). Berdasarkan wawancara yang dilakukan diketahui bahwa kedelapan subyek memiliki hubungan yang baik dengan keluarga dan orang-orang di sekitar tempat tinggalnya. Kedelapan subyek juga mendapatkan dukungan yang baik dari keluarga serta orang lain di lingkungan subyek, saat sedang menghadapi masalah dan memerlukan bantuan kedelapan subyek mendapatkan dukungan berupa semangat, materi serta saran mengenai masalah yang sedang dihadapi. Dengan adanya hubungan sosial yang baik dengan orang-orang di sekitarnya, kedelapan subyek merasakan kepuasaan dalam hubungan sosial yang dijalani.

\section{Lingkungan}

Lingkungan yaitu tempat tinggal individu. Termasuk keadaan, ketersediaan tempat tinggal untuk melakukan segala aktivitas kehidupan, sarana dan prasarana. Hubungan dengan lingkungan mencakup sumber keuangan, kebebasan, keamanan dan keselamatan fisik, perawatan kesehatan dan perawatan sosial termasuk aksesibilitas dan kualitas, lingkungan rumah, kesempatan untuk mendapatkan berbagai informasi baru maupun keterampilan, partisipasi dan kesempatan untuk melakukan rekreasi dan kegiatan yang menyenangkan di waktu luang, dan lingkungan fisik seperti polusi, kebisingan, keadaan air atau iklim, serta transportasi (WHO, 1998). Berdasarkan wawancara yang dilakukan diketahui bahwa tidak semua subyek saat ini merasakan kepuasaan terhadap kondisi lingkungan tempat tinggal. Tujuh dari delapan subyek merasakan kepuasaan terhadap lingkungannya karena merasa nyaman dan merasakan kebersihan dari lingkungannya. Sedangkan satu subyek yaitu WM merasa kurang puas dengan lingkungannya walaupun memiliki kenyamanan pada lingkungannya. Selain itu dari delapan subyek hanya lima orang subyek yaitu WL, NS, NR, KM, dan WK yang merasakan kepuasaan pada penghasilannya sedangkan tiga subyek lainnya yaitu NK, WR, dan WM merasa ketidakpuasaan pada penghasilan yang diterima.

\section{Kemandirian}

Dimensi kemandirian adalah dorongan sendiri untuk kebutuhannya, termasuk seberapa mampu partisipan dalam mengatur aktivitas sendiri, mandiri secara finansial, dapat memenuhi kebutuhan sendiri, tidak bergantung pada anak, dan merasa masih dibutuhkan (Dewi et al., 2017). Berdasarkan wawancara yang dilakukan diketahui bahwa enam orang subyek yaitu subyek WL, NS, KM, NR, WR, dan WM dapat mengatur keuangan dan aktivitasnya secara mandiri sedangkan dua subyek lainnya yaitu subyek WM dapat mengatur aktivitasnya secara mandiri tetapi keuangan yang dimiliki diatur oleh suaminya sedangkan untuk subyek NK, aktivitas dan keuangannya saat ini diatur bersama dengan anak dan istri. Walaupun tidak semua subyek dapat dengan mandiri mengatur aktivitas dan keuangannya tetapi semua subyek merasa puas dengan kemandirian yang dimiliki. 


\section{Spiritualitas}

Dimensi spiritual adalah mengembangkan dirinya secara utuh. Seberapa mampu partisipan dalam menerima kondisi fisik/sosial, kesabaran, bersyukur, dan melakukan ibadah kepada Tuhan Yang Maha Esa (Dewi et al., 2018). Berdasarkan wawancara yang dilakukan kedelapan subyek aktif untuk melakukan persembahyangan dan mengikuti kegiatan agama. Kedelapan subyek juga merasakan bahwa agama yang diyakininya memiliki pengaruh di dalam kehidupannya seharihari. Berdasarkan wawancara yang dilakukan diketahui juga bahwa semua subyek merasakan kepuasan terhadap kehidupan spiritual karena merasa bahwa agama yang diyakininya berpengaruh terhadap kehidupannya sehari-hari

\section{Pemberdayaan diri}

Dimensi pemberdayaan diri adalah keinginan untuk diberdayakan meskipun mereka sudah berada dalam usia lanjut. Seberapa mampu partisipan dalam meningkatkan kepercayaan diri dan termotivasi mengejar tujuan (Dewi et al., 2017). Berdasarkan hasil wawancara yang dilakukan diketahui bahwa delapan subyek merasa masih diberdayakan pada usianya saat ini karena merasa bahwa saran dan ide-ide yang diberikan oleh mereka masih didengarkan dan diterima baik oleh masyarakat di lingkungan subyek serta anak-anak subyek. Tujuh dari delapan subyek yaitu subyek WL, NS, KM, NK, NR, WR, WK merasa masih bermanfaat untuk orang lain karena masih dapat membantu orang di sekitar mereka, sedangkan satu subyek yaitu subyek WM merasa sudah tidak bermanfaat untuk orang lain karena usianya yang sudah tua. Berdasarkan wawancara yang dilakukan delapan subyek merasakan kepuasan pada dimensi pemberdayaan diri yang dirasakannya karena masih merasa diberdayakan walaupun usia semua subyek sudah menua.

\section{KESIMPULAN DAN SARAN}

Berdasarkan hasil penelitian dapat disimpulkan bahwa ke delapan lansia di Gianyar Bali tidak semuanya memiliki kehidupan yang berkualitas, Dengan kata lain, tidak semua dimensi yang membentuk kualitas kehidupan dapat bermakna dengan baik oleh ke delapan lansia Gianyar Bali. Dari tujuh dimensi yang ada, dimensi yang tidak dominan yang dirasakan oleh semua subyek adalah dimensi kesehatan fisik dan dimensi lingkungan. Sedangkan dimensi yang paling dominan dirasakan oleh semua subyek adalah dimensi hubungan sosial, kesejahteraan psikologis, spiritual, kemandirian, dan pemberdayaan diri.

Saran untuk penelitian selanjutnya dapat dilakukan penelitian di kota-kota lain di Indonesia yang memiliki jumlah lansia yang tinggi agar didapatkan perbandingan kualitas kehidupan lansia di kota-kota lain di Indonesia. Saran yang berkenaan secara praktis bagi lansia agar dapat memeriksakan kesehatannya secara rutin, hal ini dapat membuat kualitas kehidupan lansia menjadi lebih baik. Saran lainnya untuk keluarga dan anak-anak lansia agar tetap memperhatikan individu lansia, karena salah satu faktor yang membuat kualitas kehidupan lansia lebih bermakna adalah kehadiran serta dukungan dari orang-orang sekitarnya. Saran terakhir ditunjukan untuk pemerintah agar pemerataan fasilitas kesehatan dan kegiatan yang ditujukan untuk individu lanjut usia karena kegiatan tersebut dapat membantu individu lanjut usia merasa lebih diperhatikan di dalam lingkungannya.

\section{Ucapan Terima Kasih (Acknowledgement)}

Terimakasih penulis ucapkan kepada delapan nini dan pekak yang sudah bersedia sebagai partisipan dalam penelitian ini, serta pihak-pihak yang tidak dapat disebutkan satu persatu yang membantu dalam proses penelitiian. 


\section{REFERENSI}

Artini, N. M., Prihandhani, I. S., \& Martini, N. M. D. A. (2017). Hubungan fungsi keluarga dengan kualitas hidup lanjut usia di desa Jimbaran Kecamatan Kuta Selatan. CARING, $1(2)$ 84-90.

Diunduh

dari http://ejournal.binausadabali.ac.id/index.php/caring/article/view/10

Ayuningtias, A. U. H. (2018). Religiusitas sebagai faktor pendukung kepuasan hidup lansia di Bali. Jurnal Psikologi Mandala, 2(1), 53-61. Diunduh dari https://jurnal.undhirabali.ac.id/index.php/JPM/article/view/675

Baernholdt, M., Yan, G., Hinton, I., Rose, K., Mattos, M. (2012). Quality of life in rural and urban adults 65 years and older: Finding the national health and nutrition examination survey. The Jurnal of Rural Health, 1-9. doi: 10.1111/j.1748-0361.2011.00403.x

Creswell, J.W. (2013). Qualitative inquiry \& research design: Choosing among five approaches. Los Angeles, CA: Sage.

Dahono, Y. (2014, Oktober 02). Indonesia, peringkat bawah dalam kualitas hidup lansia. BeritaSatu. Diunduh dari https://www.beritasatu.com/iptek/214530/indonesia-peringkatbawah-soal-kualitas-hidup-lansia

Dewi, F. I. R., Rostiana., Rumawas, M. E. (2018). The assessment on model of quality of life in Indonesian elderly. Advance Science Letters, 24(1), 417-419. https://doi.org/10.1166/asl.2018.12026

Dinkes Kabupaten Gianyar. (2013). Profil kesehatan kabupaten gianyar tahun 2013. Dinas Kesehatan Kabupaten Gianyar.

Kementerian Kesehatan RI. (2017). Analisis lansia di Indonesia. Agustus 15, 2018.

Pemerintahan Kabupaten Gianyar. (2011, September 26). Gianyar Peduli Lansia. Diunduh dari https://www.gianyarkab.go.id/index.php/baca-berita/2900/Gianyar-Peduli-Lansia

Sirgy, M. J. (2012). The psychology of of quality of life, hedonic well-being, life satisfication, and eudaimonia ( $2^{\text {nd }}$ ed.). Virginia: Springer.

Sena, I. W. (2010). Implementasi konsep ngayah dalam meningkatkan toleransi kehidupan umat beragama di Bali. Diunduh dari http://sim.ihdn.ac.id/app-assets/repo/repo-dosen121802010034-16.pdf

Sun, W., Aodeng, S., Tanimoto, Y., Watanabe, M., Han, J., Wang, B., . . . Kono, K. (2014). Quality of life (QOL) of the community-dwelling elderly and associated factors: A population-based study in urban area of China. Acrhives of Gerontology and Geriatrics, 60, 311-316. doi: 10.1016/j.archger.2014.12.002

Sutari, T. (2017, Mei 16). Indonesia akan masuk daftar negara berwarga lansia terbanyak. CNN Indonesia. Diunduh dari https://www.cnnindonesia.com/nasional/20170516135543-20215181/indonesia-bakal-masuk-daftar-negara-berwarga-lansia-terbanyak

Sutikno, E. (2011). Hubungan antara fungsi keluarga dan kualitas hidup lansia. Jurnal Kedokteran Indonesia, 2(1), 1-8

Wiyono, N. H \& Djutaharta, T. (2019). Pola pengaturan tempat tinggal (living arrangement) penduduk lanjut usia: Studi kasus di Bali. Lembaga Demografi FEB UI. Diunduh dari https://ldfebui.org/wp-content/uploads/2017/02/Maret-BN-2019.pdf

World Health Organization. (1996). WHOQOL-BREF: Introduction, administration, scoring and generic version of the assessment. Geneva: World Health Organization. Diunduh dari https://www.who.int/mental_health/media/en/76.pdf

World Health Organization. (1998). Development of the world health organization WHOQOLBREF quality of life assessment. Psychological Medicine, 28(3), 551-558. doi: $10.1017 / \mathrm{s} 0033291798006667$

Wikananda, G. (2017). Hubungan kualitas hidup dan faktor resiko pada usia lanjut di wilayah kerja puskesmas Tampaksiring I Kabupaten Gianyar Bali 205. Intisari Sains Medis, 8(1), 
41-49. Diunduh dari https://www.isainsmedis.id/index.php/ism/article/view/112

Yamada, Y., Merz, L., \& Kisetrova, H. (2014). Quality of life and comorbidity among older home care clients: Role of positive toward aging. Quality of Life Research, 24(7), 16611667. doi: 10.1007/s11136-014-0899-x

Yulianti, A., Baroya, N., \& Ririanty, M. (2014). Perbedaan kualitas hidup lansia yang tinggal di komunitas dengan di pelayanan sosial lanjut usia. e-Jurnal Pustaka Kesehatan, 2(1),8794. Diunduh dari http://jurnal.unej.ac.id/index.php/JPK/article/view/601 